Nataša Pirih Svetina

Filozofska fakulteta

Univerze v Ljubljani

n.pirih@ff.uni-lj.si

\section{Mojca Schlamberger Brezar}

Filozofska fakulteta

Univerze v Ljubljani

mojca.brezar@ff.uni-lj.si

\section{Gregor Perko}

Filozofska fakulteta

Univerze v Ljubljani

gregor.perko@ff.uni-lj.si

\section{Patrice Pognan}

Institut National des langues et civilisations

orientales INALCO, Pariz

patrice.pognan@gmail.com
UDK 811:808.56

DOI: 10.4312/vestnik.8.99-111

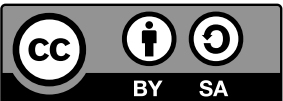

\title{
KO VSAK UPORABLJA SVOJ LASTNI JEZIK IN RAZUME SVOJEGA SOGOVORCA
}

Medjezikovno razumevanje je oblika sporazumevanja, v katerem se vsak sodelujoči izraža v svojem jeziku in razume tistega, ki ga govori drugi (Doyé 2005).

V prispevku avtorji predstavljamo svoj pogled na medjezikovno razumevanje, ki smo ga trije oblikovali kot govorci slovanskega jezika, slovenščine, in hkrati dobri poznavalci vsak enega romanskega jezika (francoščina, italijanščina), eden pa kot rojeni govorec francoščine in hkrati odličen poznavalec češčine, slovaščine, lužiške srbščine in poljščine. Slovanske ali romanske osnove ali korenine na eni strani, na drugi pa poznavanje romanskih oziroma slovanskih jezikov nam omogočajo, da se med seboj sporazumevamo brez nekega zares skupnega jezika, ki bi bil v današnjem času pričakovano v večini primerov angleščina. 
Pojem medjezikovnega razumevanja, s katerim so se v Evropi, predvsem v romanskem svetu, začeli ukvarjati kmalu po letu 2000, je v našem prostoru relativna novost: ${ }^{1}$ zaradi vsesplošne razširjenosti angleščine in relativne lagodnosti pri njenem učenju, poučevanju in sprejemanju nismo veliko premišljevali o tem, kako bi se brez nje sporazumevali s svojimi romanskimi sosedi, mlajše generacije, rojene v Sloveniji po letu 1990, pa celo ne, da bi se brez nje sporazumevale z bližnjimi slovanskimi sosedi.

$\mathrm{V}$ začetku prispevka bomo predstavili definicije medjezikovnega razumevanja in sporazumevanja, njegovo umestitev v politiko več- in raznojezičnosti ter družbene razsežnosti pojava, sledila pa bo predstavitev možnih praks v razredu, od katerih smo jih del izvedli v okviru usposabljanja za učitelje slovenščine kot tujega jezika. ${ }^{2}$

\section{MEDJEZIKOVNO RAZUMEVANJE TER SPORAZUMEVANJE - DEFINICIJE IN ZAČETKI}

Kot kaže uvodni moto (Doyé 2005), je medjezikovno razumevanje, kar je slovenski prevod za francosko intercompréhension oziroma angleško intercomprehension, sporazumevalna praksa, pri kateri dve osebi uporabljata (govorita) vsaka svoj jezik in se med seboj sporazumeta - ne da bi sploh znali ali se prej (na)učili jezika svojega sogovorca. Pri tem je običajno mišljeno, da udeleženci v sporazumevalni situaciji uporabljajo vsak svoj prvi oz. materni jezik, lahko pa gre tudi za govorce, ki so se zelo dobro naučili določenega tujega jezika in prek njega vstopajo v sporazumevanje. Tako (spo)razumevanje je možno med govorci sorodnih ali bližnjih jezikov in je npr. običajna praksa govorcev iz Skandinavije (npr. Robert 2004). Robert (2004) poudarja, da je medjezikovno razumevanje med uporabniki švedščine, danščine in norveščine vezano na sporazumevalni postopek, ko se vsak od govorcev izraža v svojem jeziku, sogovorci pa ga razumejo. Tako sporazumevanje ne predvideva rabe nekega tretjega jezika, ki bi ga vsi razumeli (npr. angleščine), in ne privilegira nobenega jezika (Robert prav tam). Robert tudi navaja, da je ob vstopu Portugalske in Španije v Evropsko unijo ponovno vzcvetela ideja evropske večjezičnosti in raznojezičnosti na osnovi medjezikovnega razumevanja med romanskimi jeziki (Robert 2008), o tem več v nadaljevanju.

O sorodnih jezikih govorimo v okviru jezikovnih skupin oziroma jezikovnih družin, kjer so v obliki družinskega drevesa združeni sorodni jeziki. Ena takih je skupina

1 V sklepu prispevka sppregovorimo o projektu Referenčni okvir za pluralistične pristope k jezikom in kulturam (ROPP), ki pod okriljem Sveta Evrope poteka od leta 2004, v Sloveniji pa je bilo prvo usposabljanje zanj na Zavodu za šolstvo RS, ki projekt koordinira v Sloveniji, izvedeno leta 2014. Projekt je v Evropi znan pod imenom CARAP (fr. okrajšava) ali FREPA (ang. okrajšava). Cilj projekta je usposobiti učitelje za uporabo didaktičnih pristopov, $\mathrm{s}$ katerimi se v procesu učenja povezuje znanja dveh ali več jezikov in kultur.

2 Delavnica na temo medjezikovnega razumevanja med slovanskimi in romanskimi jeziki je bila izvedena $\mathrm{v}$ okviru stalnega strokovnega spopolnjevanja učiteljev slovenščine kot tujega jezika na Centru za slovenščino kot drugi in tuji jezik Filozofske fakultete Univerze v Ljubljani junija leta 2016. 
indoevropskih jezikov, v katero sodijo tudi največje evropske družine jezikov: slovanska, germanska in romanska. Sorodni jeziki so torej tisti, ki pripadajo isti jezikovni skupini, vendar so si tudi jeziki znotraj ene skupine lahko med seboj bolj podobni, tudi bližnji, nekateri pa bolj oddaljeni. Med slovanskimi jeziki so si tako načeloma bližji tisti jeziki, ki geografsko in zgodovinsko pripadajo eni od ožjih skupin slovanskih jezikov, npr. južno-, vzhodno- ali zahodnoslovanski skupini, pri čemer pa (na podlagi rezultatov raziskav) prihaja tudi do odstopanj - slovenščina in slovaščina sta si tako npr. bližji (Golubović 2016) kot slovenščina in bolgarščina (prav tam), čeprav slednji obe pripadata južnoslovanski skupini jezikov, slovaščina pa zahodnoslovanski. Podobno tudi Schlamberger Brezar in dr. (2015: 12-16) ugotavljajo, da sta bližnja jezika slovenščini recimo hrvaščina in slovaščina, medtem ko je ruščina kot vzhodnoslovanski jezik bolj oddaljena. ${ }^{3}$ Za medjezikovno razumevanje - v ang. tudi mutual intelligibility (Golubović 2016) - sta torej pomembna koncepta bližine, povezanosti in sorodnosti med jeziki na eni ter medsebojne oddaljenosti na drugi strani. Pri tem različni avtorji razlikujejo tudi med inherentno razumljivostjo (ang. inherent intelligibility) in usvojeno razumljivostjo (ang. acquired intelligibility). Slednja dejansko ni predmet našega razpravljanja, saj predstavlja rezultat učenja dveh (lahko) popolnoma nepovezanih jezikov, inherentna razumljivost pa je možna zgolj med bližnjimi jeziki in ni posledica učenja nekega konkretnega jezika (Golubović 2016: 17).

Medjezikovno (spo)razumevanje naj bi bilo torej možno predvsem med rojenimi govorci sorodnih oz. bližnjih prvih jezikov. ${ }^{4} \mathrm{~V}$ angleščini se za tovrstno razumevanje uporablja tudi izraz intercomprehension of related languages (Candelier 2012). Medjezikovno (spo)razumevanje poteka med uporabniki jezikov, medsebojna podobnost, sorodnost in bližina jezikov pa je potencial, ki tovrstno (spo)razumevanje omogoča. V tej definiciji se jasno začrtata dve točki: medjezikovno razumevanje vključuje tako govorno kot pisno sporazumevanje, ki temelji na vzajemnem razumevanju, torej na recepciji povedanega ali zapisanega; izključuje pa produkcijo tujega jezika, torej govorjenje in pisanje v tujem jeziku. Posebej je treba izpostaviti prvo točko, ker je za večino sporazumevalnih situacij značilno, da glede na okoliščine prevladuje bodisi pisno bodisi govorno sporazumevanje oziroma da eden od načinov izražanja dominira. Druga točka pa je hkrati tudi ena bistvenih prednosti medjezikovnega razumevanja, saj poudarja, da se od govorcev ne zahteva,

3 Če s tem v zvezi citiramo Meilleta (1965: 3): « Le classement des langues slaves en dialectes ressortira de l'exposé qui va suivre. Il y a 3 groupes. Le groupe occidental: tchèque, sorabe, polabe et polonais, est net et se reconnaît à toute une série de particularités communes. Le grand et le petit russe forment une unité plus nette encore et font l'effet de deux formes d'un seul et même dialecte. Les parlers méridionaux dits bulgares, serbo-croates et slovènes ont en commun peu d'innovations identiques tout à fait caractéristiques, mais se laissent aussi grouper ensemble sans violence ». (V prevodu: Razdelitev slovanskih jezikov v narečja bo razvidna iz nadaljnjega besedila. Obstajajo tri skupine. Zahodna skupina, češčina, lužiška srbščina, polabščina in poljščina, je jasno razdeljena in v njej lahko prepoznamo celo serijo skupnih značilnosti. Ruščina in beloruščina tvorita jasnejšo enoto in predstavljata dve obliki istega dialekta. Južni govori so bolgarski, srbohrvaški in slovenski in jim je skupnih malo identičnih značilnih inovacij, a se jih da združiti, ne da bi jim delali silo.)

4 Načeloma se lahko dva govorca med seboj sporazumeta, tudi če ne govorita oba svojih prvih jezikov, ampak uporabljata dva sorodna, lahko tudi njima tuja jezika. V tem primeru bi intercomprehension pomenil tudi razumevanje tujega jezika na osnovi nekega drugega prej (na)učenega tujega jezika. 
da bi se bili sposobni pisno ali govorno izražati v tujem jeziku (Doye 2005), ampak vsak od udeležencev govori ali piše v svojem jeziku, se pa med seboj kljub temu razumejo. Medjezikovnemu (spo)razumevanju sorodni koncepti so npr. ang. receptive multilingualism, plurilingual communication (Golubović 2016: 17-18). ${ }^{5}$

Govorci sorodnih jezikov razpolagajo $\mathrm{z}$ do neke mere prekrivnim znanjem, védenjem in zavedanjem o jeziku oziroma jezikih na leksikalni, fonološki, morfološki in skladenjski ravnini, tem pa lahko prištejemo še diskurzivne, besedilne in kulturne kazalce, ki so povezani z jezikovno skupnostjo, ki uporablja določen jezik in ki je hkrati kulturno določena. Ti elementi so pogosto spregledani, ker je jezikovna sorodnost večkrat kot prednost obravnavana kot problem, predvsem zaradi možnosti negativnega jezikovnega prenosa oziroma interference ter lažnih prijateljev. Dejansko pa, kot kaže tudi koncept medjezikovnega (spo) razumevanja, bi bila lahko pojmovana kot velik potencial, možnost in priložnost, saj omogoča lažjo recepcijo drugega jezika ter posledično lažje medsebojno razumevanje.

Začetki koncepta medjezikovnega razumevanja segajo precej v preteklost: po Escudéju (2010: 35) naj bi pojem »intercompréhension« okrog leta 1913 uporabil provansalski jezikoslovec Jules Ronjat, ki je govoril o medjezikovnem razumevanju kot sposobnosti govorcev, da razumejo dialekte različnih jezikov iste jezikovne družine, kar je bila $v$ francoskem okolju edina možnost za preživetje. ${ }^{6}$ Koncept medjezikovnega razumevanja so uvedli francoski avtorji v okviru poučevanja večjezičnosti. Kot pravi J. M. Robert (2008: 9), v jezikoslovju slabo razlikujejo med pluri- in multilingvizmom, pojma sta običajno rabljena sinonimno. Tako je tudi v slovenščini, kjer običajno za oba neustrezno uporabljamo kar termin »večjezičnost«, čeprav plurilingvizem lahko ustrezno prevedemo z raznojezičnostjo (SEJO 2011: 9), ki označuje koncept posameznikove sporazumevalne zmožnosti oziroma kompetence za rabo različnih jezikov (franc. plurilinguisme, ang. plurilingualism). Po SEJO (prav tam) naj ta ne bi bila zgolj funkcionalna nuja posameznika v moderni družbi, ampak tudi bistvena sestavina demokratičnega vedênja. Za razliko od raznojezičnosti kot značilnosti posameznika se pojem večjezičnost nanaša na družbo in rabo več različnih jezikov v njej (ang. multilingualism; franc. une société multilingue). Vsi ti izrazi, kot tudi dokumenti, npr. Skupni evropski jezikovni okvir za jezike, ter koncepti, povezani z njimi, so nastali kot rezultat politike jezikovnega izobraževanja v na novo povezani Evropi, predvsem pa v službah Sveta Evrope. Ob razmišljanju o enotnem, skupnem evropskem jeziku, ki bi omogočil sporazumevanje v jezikovno zelo raznoliki in pestri Evropi, so se seveda kmalu pojavili tudi nasprotniki le-tega, sploh zato, ker se je na njegovem mestu, torej na mestu lingue francae, zaradi različnih razlogov zelo hitro ustoličila angleščina (SEJO 2011: 9). V krogu francoskih jezikoslovcev-didaktikov, nasprotnikov angleščine kot skupnega evropskega jezika, se je razvil pristop medjezikovnega razumevanja med romanskimi jeziki v 90-ih letih 20. stoletja (Blanche-Benveniste

5 Prvi izraz bi v slovenščino lahko prevedli kot receptivna večjezičnost, drugega pa kot raznojezično sporazumevanje. Glej tudi v nadaljevanju.

6 Francoščina kot edini jezik poučevanja v laični obvezni šoli je na francoskem teritoriju spodrivala dialekte, mnogo otrok $v$ tem času ob prihodu $v$ šolo ni govorilo francosko (Escudé prav tam). 
1997). V svojem bistvu predstavlja poskus oživitve srednjeveške tradicije medsebojnega razumevanja uporabnikov romanskih jezikov (to je potekalo tudi s pomočjo oziroma prek latinščine - avtorji metode aludirajo na Ecov roman Ime rože). Hkrati pa je šlo tudi za poskus ponovnega ovrednotenja romanskih jezikov na področju mednarodnih odnosov in izmenjav (politična odločitev v spopadu $\mathrm{z}$ angleščino). V naslednjem desetletju so nastajali različni evropski projekti, ki naj bi pripomogli tako pri seznanjanju s potencialom za medjezikovno razumevanje kot tudi razvijali didaktične pristope za njegovo poučevanje. Med njimi so npr. projekt Miriadi-Galatea z Louise Dabène ${ }^{7}$, Eurocomrom ${ }^{8}$ ali pa MICReLa ${ }^{9}$. Projekt MICReLa si je za cilj zadal odgovoriti na vprašanje o stopnji medsebojne razumljivosti med bližnjimi oz. sorodnimi jeziki v Evropi in razlogih, ki nanjo vplivajo. V obravnavo so bili zajeti jeziki treh največjih evropskih jezikovnih družin: germanske, romanske in slovanske. Posebej za germanske jezike je na salzburški univerzi potekal projekt Iglo ${ }^{10}$.

\section{TEORETIČNI OKVIR ZA POUČEVANJE MEDJEZIKOVNEGA RAZUMEVANJA}

Za boljše preučevanje medjezikovnega razumevanja je pomembno ločevati med jezikovno zmožnostjo ali kompetenco in jezikovno performanco, ki sta običajno v ospredju raziskovanja vsakega jezikovnega pojava. Kompetenca ali zmožnost je potencial za razumevanje drugega jezika, ne da bi se ga (na)učili, po C. Blanche-Benveniste (1997) gre dejansko za delno kompetenco. $Z$ vidika performance je medjezikovno razumevanje definirano kot dejavnost oseb, ki se sporazumevajo tako, da uporabljajo vsaka svoj jezik, pri tem pa razumejo jezik druge osebe. Gre za alternativo ali dopolnjevanje načela linguae francae.

Lingua franca ima seveda prednost pred vsemi drugimi načini sporazumevanja med ljudmi z različnimi prvimi jeziki: če vsi udeleženci večjezičnega multikulturnega srečanja razumejo in govorijo isti jezik, to zelo olajša njihovo medsebojno sporazumevanje. Vendar je splošno zanimanje za linguo franco, ki je bilo močno še na prehodu med stoletjema, naredilo prostor za različne poglede in kritike: $\mathrm{v}$ didaktičnih krogih začenjajo spoznavati, da so se prednostim pridružile tudi slabosti, med katerimi se izpostavljajo predvsem jezikovni imperializem (angleščine), slabost rabe linguae francae, odrezane od kulturnih korenin oz. kulturno izpraznjenost tega jezika, površnost in površinskost, tudi nenatančnost pri izražanju (Doye 2005), čemur se pridružuje še podcenjevalni odnos do drugih jezikov.

Z jezikovno politiko medjezikovnega razumevanja in sporazumevanja bi lahko presegli te težave, saj poleg že omenjenih prednosti prinaša tudi politično korektnost in se povsem vključuje v evropski kontekst (Doye 2005): ohranjanje jezikovne raznolikosti,

7 https://www.miriadi.net/en/projects

8 http://www.eurocom.uni-frankfurt.de/

9 http.let.rug.nl/gooskens/project/

10 https://www.uni-salzburg.at/index.php?id=24808 
preprečevanje dominacije enega samega jezika, promocija raznojezičnosti in večjezičnosti (SEJO 2011: 8-9 in zgoraj). Medjezikovno razumevanje temelji na trdnih psiholoških komponentah, ki vključujejo interakcijo med jezikovnimi sposobnostmi, in zmožnost, da uporabljamo znanja, ki smo jih pridobili v preteklosti. V optiki medjezikovnega razumevanja se vsa znanja z vseh področij združujejo, da na ta način lahko olajšajo razumevanje formalnih sporočil v jeziku, ki se ga nismo naučili (Doye 2005).

Didaktični pristopi k medjezikovnemu razumevanju predvidevajo, rezultati raziskav pa tudi potrjujejo (Golubović 2016), da lahko pouk oz. poučevanje in opozarjanje na podobnosti med jeziki olajša pridobivanje zmožnosti medjezikovnega razumevanja. Med preizkušenimi didaktičnimi pristopi, ki delujejo v prid medjezikovnemu sporazumevanju, bi izpostavili spodbujanje, motivacijo za razumevanje sogovorca, senzibilizacijo za medjezikovno sporazumevanje, pridobivanje oziroma poglabljanje sposobnosti medjezikovnega sporazumevanja in pospeševanjem slednje. Medjezikovno razumevanje je dejansko praksa, ki se je da naučiti. Didaktika medjezikovnega razumevanja je del Skupnega evropskega jezikovnega okvira (SEJO 2011), ki poudarja, da se jezikov ne učimo izolirano in ločeno, ampak da iščemo podobnosti med njimi in poskušamo nove podatke o jeziku navezati na že znano: govorci sorodnih jezikov npr. že imajo inventar v lastnem jeziku, ki ga morajo zgolj prenesti na tuji jezik (Doye 2005; Klein, Stegmann 2004).

\section{4}

RAVNINE MEDJEZIKOVNEGA RAZUMEVANJA

Pri medjezikovnem razumevanju je v ospredju transverzalni pristop in izkoriščanje obstoječih znanj. Upoštevanje (in izkoriščanje) bližine in sorodnosti jezikov na eni strani ter osredotočanje na delne zmožnosti pri učencih (npr. samo na razumevanje povedanega, ne pa tudi na produkcijo) omogoča načrtovanje transverzalne perspektive. Zelo enostavno in plodno je širiti to metodologijo na več jezikov iste družine. Hkratni študij več bližnjih jezikov, čeprav ni poglobljen, prinaša jezikovno, kognitivno, kulturno in človeško obogatitev, kar je zelo stimulativno.

Metodologija za poučevanje medjezikovnega razumevanja se uresničuje na več področjih, ki so tudi del SEJA in jih skozi Doyevo klasifikacijo področij znanja in védenja (Doye 2005) navajamo v nadaljevanju:

1) Poznavanje kulture se osredotoča na poznavanje specifične kulture dežele, v kateri se govori ciljni jezik. V poznavanje kulture sodi tudi poznavanje stereotipov. Jezikovno sporočilo razumemo in interpretiramo znotraj specifičnega kulturnega konteksta.

2) Poznavanje sporazumevalne situacije vključuje tipične sporazumevalne situacije (npr. pri nakupovanju) in rutine (npr. pozdravi), ki jih na določen način opravljajo govorci jezika.

3) Poznavanje vedênja, obnašanja, izražanja čustev, kretenj, mimike, kar vse lahko bistveno pomaga pri razumevanju izrečenega. 
4) Pragmatično znanje vključuje prepoznavanje jezikovnih funkcij in govornih dejanj, kot so npr. pritrjevanje, strinjanje, svetovanje, ukazovanje, obljuba ipd.

5) Poznavanje sistema pisave in poznavanje povezave med zapisom in govorom. Rezultati raziskav med drugim kažejo (Golubović 2016), da so si jeziki iste jezikovne družine, če se zapisujejo z drugačnim črkopisom, avtomatično bolj oddaljeni od jezikov iste jezikovne družine, ki se zapisujejo $\mathrm{z}$ enakim črkopisom. V delavnici, izvedeni med skupino slovenistov, smo tako izvedli poskus razumevanja besedila $\mathrm{v}$ makedonščini, ki je bilo delu skupine posredovano v originalnem cirilskem črkopisu, drugemu delu pa transliterirano v latinično pisavo. Pričakovano je bilo razumevanje besedila, zapisanega $\mathrm{v}$ cirilici, bistveno težje od razumevanja istega besedila, zapisanega $v$ latinični pisavi.

Јован ги положи сите испити пред време и сега е слободен до септември. Размислувадаоди на одмор некаде на неколку дена, но сѐ уште не испланирал ништо. Би сакал, ако може, да заработи некој денар во слободниот период. Може да работи како преведувач, бидејќи добро знае барем неколку словенски јазици. Не му е тешко да преведува на македонски од руски, полски, чешки, српски, хрватски, словенечки и словачки. И обратно, се разбира. Многу фирми имаат потреба од преведувачи токму за овие јазици. Ете, минатата недела само во еден весник видел неколку огласи и конкурси за ова работно место.

Odlomek besedila v makedonščini.

Jovan gi položi site ispiti pred vreme i sega e sloboden do septemvri. Razmisluva da odi na odmor nekade na nekolku dena, no sè ušte ne isplaniral ništo. Bi sakal, ako može, da zaraboti nekoj denar vo slobodniot period. Može da raboti kako preveduvač, bidejḱi dobro znae barem nekolku slovenski jazici. Ne mu e teško da preveduva na makedonski od ruski, polski, češki, srpski, hrvatski, slovenečki i slovački. I obratno, se razbira. Mnogu firmi imaat potreba od preveduvači tokmu za ovie jazici. Ete, minatata nedela samo vo eden vesnik videl nekolku oglasi i konkursi za ova rabotno mesto.

Isto besedilo, zapisano z latinično pisavo.

6) Fonološko znanje oziroma prepoznavanje fonološkega sistema ali celo glasovnega razvoja različnih jezikov vključuje možne izpeljave in povezave med jeziki (leksem $p Q t$ je v razvoju južnoslovanskih jezikov pripeljal do dveh različic z enakim pomenom: pot in put).

7) Slovnično znanje se razširi na prepoznavanje skladenjskih in obliko-skladenjskih zakonitosti.

8) Poznavanje leksike vključuje mednarodni besednjak (internacionalizmi oziroma transparentne besede) in besednjak, ki je skupen npr. dvema sorodnima jezikoma. 


\section{PRIMERI PRAKSE}

Eden od praktičnih pristopov, ki se je uveljavil predvsem v okviru metode EuroCom (-Rom, -Slav ali -Germ) (Klein, Stegman 2004) in ki dobro ilustrira tudi zgornje ravni, po katerih je po eni strani možno ocenjevati sorodnost oz. jezikovno bližino, po drugi pa tudi spodbujati medjezikovno razumevanje, je Metoda sedmih sit. Gre za presejalno metodo, ki jo lahko izvedemo ob vsakem besedilu, tako poslušanem kot zapisanem. S prvim sitom odberemo mednarodne besede, to so tiste, ki jih kot tujke uporabljamo v različnih jezikih (poleg besed latinskega izvora, so lahko to tudi besede grškega ali angleškega izvora). $\mathrm{Z}$ drugim sitom označimo $\mathrm{v}$ okviru romanskih jezikov panromanske besede, v okviru slovanskih pa panslovanske besede. Tretje sito »zadrži« fonetično sorodne besede, v katerih se kaže razvoj v danem jeziku - npr. lat. tabula, fr. Table; it. schuola, fr. école. Pri četrtem situ smo pozorni na besede, ki so sorodne, pa se pišejo ali izgovarjajo drugače, npr. famiglia, famille, familia. Peto sito se osredotoča na prepoznavanje skladenjskih značilnosti jezikov, npr. besedni red ali oziralni odvisniki, gerundij kot nadomestilo za podredni stavek ipd., šesto na oblikoslovje (določni, nedoločni člen), kar ostane na sedmem situ, je preostanek, lasten zgolj danemu jeziku.

Preizkusimo metodo na spodnjem besedilu!

$$
\begin{aligned}
& \text { Carlo e'un teenager simpatico e gentile. } \\
& E^{\prime} \text { il pici piccolo della sua famiglia. } \\
& \text { Suo papa' ha un bel supermercato } e \\
& \text { sua mamma rivende oggetti per animali- }
\end{aligned}
$$

- Kaj se zgodi, ko besedilo damo skozi prvo sito $\mathrm{z}$ »internacionalizmi«? Napišite te besede.

- Katere so panromanske besede, ki ostanejo na drugem situ?

- Tretje sito - pobere fonetično sorodne besede.

- Kaj ostane na situ »pisava in izgovarjava«?

- Kateri so v stavku skladenjski elementi, ki so skupni romanskim jezikom?

- Naslednje sito predstavlja oblikoslovne elemente. Kateri so?

- Zadnje sito zadrži »evropone«. Katere predpone in pripone opazite?

- Kaj na koncu ni ostalo na situ?

Primer, kako je bila metoda sedmih sit uporabljena na delavnici v okviru izobraževalnega seminarja. 
Drugi možni pristop k poučevanju medjezikovnega razumevanja je uporaba neznanih jezikov iste družine $\mathrm{v}$ znanih kontekstih, ki pospešujejo razumevanje. $\mathrm{V}$ ta namen smo v okviru Seminarja za izobraževanje učiteljev slovenskega jezika, ki delujejo v tujini v delavnici predstavili besedilo o Ljubljani (povzeto po Wikipediji), ki je predstavljalo znano tematiko, $v$ jezikih, ki sodelujočim niso bili znani (vsak udeleženec je dobil besedilo v jeziku, ki ga ne pozna), in sicer v katalonščini, galicijščini, romunščini, francoščini, španščini, portugalščini in furlanščini. Ustrojev posameznega jezika vnaprej nismo predstavljali. Slušatelji so glede na podatke, ki so jim že znani o slovenskem glavnem mestu, odkrivali izrazna sredstva v prej naštetih jezikih. Skupaj smo izdelali kratek slovarček osnovnih besed (npr. katere so besede, s katerimi poimenujemo prebivalstvo, grad, potres, zgodovina, arhitektura, ipd.) ter glasovne premene, ki se dogajajo med prehodi enega jezika v drugega pri besedah, ki bi lahko imele isti izvor. Tabelo prilagamo v informacijo (Tabela 1).

Za študij, ki spodbuja logiko medjezikovnega sporazumevanja, se že dolgo zavzemajo na INALCO-ju (Institut National des Langues et Civilisations Orientales), kjer študentom slovanskih jezikov, npr. hrvaščine in srb̌̌čine, svetujejo, da se lotijo še slovenščine, slovaščine, tudi češčine, saj jim poznavanje enega srednjeevropskega slovanskega jezika odpira vrata tudi v druge. Ta koncept smo skušali uresničiti v bilateralnem projektu Proteus 2012-2013 s ciljem izdelave slovenske slovnice za francoske govorce, kjer zapišemo: »to (medjezikovno) razumevanje je različno glede na jezike, vendar tudi če je razlika velika, tudi če stiki z drugim jezikom niso (več) v navadi, obstaja skupni fond, ki bi moral Slovanom omogočati, da se sporazumevajo ali še bolje, da dostopajo do informacij brez uporabe angleščine. Žal to ni splošno razširjeno dejstvo. «11 (Schlamberger Brezar in dr. 2015:13).

$\mathrm{V}$ poučevanje slovanskih jezikov, med drugim tudi v poučevanje slovenščine v okviru lektoratov slovenskega jezika na univerzah po svetu, bi bilo smiselno vključiti principe medjezikovnega razumevanja - npr. seznanjanje učečih se z osnovnimi principi diahrone lingvistike v slovanskih, germanskih ali romanskih jezikih. Ni pa zanemarljiv tudi politični in kulturno-sociološki vidik: $v$ svetu, kjer angleščina prevladuje kot lingua franca, je še kako pomembno, da se med učečimi se različnih jezikov spodbuja načeli raznojezičnosti in večjezičnosti ter se tudi z zgledom medsebojnega (spo)razumevanja v bližnjih jezikih istih jezikovnih družin (slovanske, romanske in germanske) daje prednost pred enostavnostjo rabe osiromašenega sporazumevanja v tretjem jeziku. Pluralistični didaktični pristopi, ki jih prinaša v uvodu že omenjeni Referenčni okvir za pluralistične pristope

11 V izvirniku se citat glasi: « Cette compréhension peut être variable suivant les langues considérées, mais même si la distance est grande, même s'il n'y a pas (ou plus) l'habitude du contact de l'autre langue, il y a un fond commun qui devrait permettre d'éviter entre Slaves le recours à l'anglais pour communiquer ou encore mieux pour accéder à une information. Malheureusement, ce n'est pas ce qui est fait en général. » 
k jezikom in kulturam (ROPP) (Candelier 2012), razvijajo učenčeve raznojezične in medkulturne zmožnosti. Hkratno usvajanje več različnih jezikov in kultur spodbujajo in omogočajo medkulturni pristop (ang. intercultural approach; Byram 2003), prebujenje v jezike (ang. awakening to languages), integrirani didaktični pristopi k različnim jezikom (ang. integrated didactic approaches to different languages) in medsebojno razumevanje med bližnjimi jeziki, ki je prav predmet tega prispevka. V času nastajanja le-tega poteka redakcija slovenskega prevoda Referenčnega okvira za pluralistične pristope k jezikom in kulturam. S pomočjo opisnikov, ki opisujejo posameznikove (učenčeve) raznojezične in medkulturne zmožnosti v smislu njegovega znanja in spretnosti v različnih jezikih ter stališč do njih, bodo slovenskemu izobraževalnemu prostoru zelo približani pluralistični didaktični pristopi pri poučevanju jezikov, s tem pa, upamo tudi bolj na široko odprta pot tudi za metodo (spo)razumevanja med bližnjimi jeziki.

Tabela 1: Primer tabele, v katero udeleženci vpisujejo besede, ki so jih prepoznali v besedilu.

Dopolnite slovarček, lahko vnesete tudi besede, katerih pomen uganete iz sobesedila.

\begin{tabular}{|l|l|l|l|l|l|l|l|l|}
\hline slovenščina & francoščina & furlanščina & galicijščina & italijanščina & katalonščina & portugalščina & romunščina & španščina \\
\hline prebivalstvo & $\begin{array}{l}\text { Population, } \\
\text { habitants }\end{array}$ & popolazion & poboación & populazione & població & população & locuitor & $\begin{array}{l}\text { habitantes, } \\
\text { población }\end{array}$ \\
\hline župan & maire & $/^{*}$ & alcalde & sindaco & alcalde & prefeito & primar & el alcalde \\
\hline cerkev & église & plêf & igrexa & chiesa & església & igreja & biserica & iglesia \\
\hline grad & chateau & $/^{*}$ & & castello & castell & castelo & castel & castillo \\
\hline potres & $\begin{array}{l}\text { Tremblement } \\
\text { de terre }\end{array}$ & $/^{*}$ & $\begin{array}{l}\text { Tremore de } \\
\text { terra }\end{array}$ & terremoto & terratrèmol & $\begin{array}{l}\text { Tremor de } \\
\text { terra }\end{array}$ & curtemur & terremotto \\
\hline reka & rivière & flum & rio & fiume & riu & rio & raul & rio \\
\hline arhitektura & architecture & architeture & arquitectura & architettura & arquitectura & arquitectura & arhitectură & arquitectura \\
\hline zgodovina & histoire & storie & historia & storia & història & historia & istorie & historia \\
\hline srednji vek & Moyen-âge & Etât di Mieç & Idade media & Medioevo & Edat mitjana & Idade média & Evul mediu & Edad media \\
\hline
\end{tabular}

*/ ni bilo na razpolago $v$ dokumentu

\section{LITERATURA}

BLANCHE-BENVENISTE, Claire/André VALLI (1997) Une grammaire pour lire en quatre langues. L'intercompréhension: le cas des langues romanes. Le français dans le monde - Recherches et applications. p. 33-37.

BYRAM, Michael (ed.) (2003) Intercultural Competence. Strasbourg: Council of Europe.

CANDELIER, Michel et. alt. (2012) FREPA - A Framewor of Reference for Pluralistic Approaches to Languages and Cultures. Competences and Resources. Graz: ECML. 
DOYÉ, Peter (2005) L'intercompréhension - Guide pour l'élaboration des politiques linguistiques éducatives de l'Europe - De la diversité linguistique à l'éducation plurilingue (Étude de référence). Strasbourg: Conseil de l'Europe.

ESCUDÉ, Pierre/Pierre JANIN (2010) L'intercompréhension, clé du plurilinguisme. Pariz: Clé international. Coll. Didactique des langues étrangères.

GOLUBOVIĆ, Jelena (2016) Mutual intelligibility in the Slavic language area. Groningen: University of Groningen.

KLEIN, Horst G. (2007) Où en sont les recherches sur l'eurocompréhension? http:// www. eurocomresearch. net/ lit/ Klein\%20FR. htm

KLEIN, Horst G. (2004) L'eurocompréhension (EuroCom), une méthode de compréhension des langues voisines, Ela $\mathrm{n}^{\circ} 136$, p. 403-418.

KLEIN, Horst G./T. D. STEGMANN (2000) EuroComRom - Die sieben Siebe : Romanische Sprachen sofort lesen können. Aachen (Éd. EuroCom vol. 1).

KLEIN, Horst G./T. D. STEGMANN (2004) Les sept tamis - lire les langues romanes dès le départ. Avec uneintroduction à la didactique de l'eurocompréhension. Shaker, (Éd. EuroCom vol. 6).

MEILLET, Antoine (1965) Le slave commun, Pariz: Honoré Champion.

ROBERT Jean-Michel (2004) Les langues voisines en Scandinavie, Ela. Études de linguistique appliquée 4/2004 ( $\mathrm{n}^{\circ}$ 136), p. 465-476, URL: www.cairn.info/revue-ela-2004-4-page-465.htm.

ROBERT Jean-Michel (2008) L'anglais comme langue proche du français? Ela. Études de linguistique appliquée 1/2008 ( ${ }^{\circ}$ 149), p. 9-20, URL: www.cairn.info/revue-ela-2008-1-page-9.htm.

SCHLAMBERGER BREZAR, Mojca/Gregor PERKO, Patrice POGNAN (2015) Les bases de la morphologie du slovène pour locuteurs francophones. Ljubljana: Filozofska fakulteta.

Skupni evropski jezikovni okvir (2011) Ljubljana: Ministrstvo za izobraževanje, znanost in šport.

TEYSSIER, Paul (2004) Comprendre les langues romanes. Pariz: Chandeigne.

\section{Spletne strani}

Euromania

http://www.eurom5.com/p/chisiamo-fr/intercomprensione

(datum dostopanja julij-november 2016)

IGLO

https://www.uni-salzburg.at/index.php?id=24808

(datum dostopanja julij-november 2016) 
Miriadi

https://www.miriadi.net/activity/evaluation-comprendre-texte-en-roumain

http://www.ecml.at/Portals/1/documents/intercomprehension-2015_enligne.pdf

http://lingalog.net/dokuwiki/intercomprehension/rcslr/ateliers/ardechois

(datum dostopanja julij-november 2016)

\section{Eurocom}

http://www.eurocom.uni-frankfurt.de/

(datum dostopanja julij-november 2016)

\section{MICRELA}

http://www.let.rug.nl/gooskens/project/

(datum dostopanja julij-november 2016)

\section{SEJO}

http://www.mizs.gov.si/si/delovna_podrocja/urad_za_razvoj_izobrazevanja/jezi-

kovno_izobrazevanje/skupni_evropski_jezikovni_okvir/

(datum dostopanja julij-november 2016)

Wikipedia - Ljubljana

Slovenščina https://sl.wikipedia.org/wiki/Ljubljana

Francoščina https://fr.wikipedia.org/wiki/Ljubljana

Furlanščina https://fur.wikipedia.org/wiki/Lubiane

Galicijščina https://gl.wikipedia.org/wiki/Liubliana\#Historia

Italijanščina https://it.wikipedia.org/wiki/Lubiana

Portugalščina https://pt.wikipedia.org/wiki/Liubliana

Romunščina https://ro.wikipedia.org/wiki/Ljubljana\#Etimologie

Španščina https://es.wikipedia.org/wiki/Liubliana\#Organizaci.C3.B3n_pol.

C3.ADtico-administrativa

\section{POVZETEK}

Medjezikovno sporazumevanje je sporazumevalna praksa, pri kateri dve osebi govorita vsaka svoj jezik in se med seboj sporazumeta, ne da bi se prej (na)učili jezika svojega sogovorca. Običajno je to mogoče pri jezikih, ki pripadajo isti jezikovni družini, na primer med slovanskimi, romanskimi ali germanskimi jeziki. V članku predstavljamo pojem medjezikovnega razumevanja kot alternativo sporazumevanju v angleščini kot lingui franci. Tako sporazumevanje je od nekdaj obstajalo med Skandinavci, prvo metodo pa so razvili za romanske jezike (EuRomCom) v začetku 21. stoletja. Danes obstaja več metod tudi za germanske in slovanske jezike. V članku predstavimo nekatere od njih, pa tudi možne prakse za utrjevanje medjezikovnega sporazumevanja.

Ključne besede: Medjezikovno razumevanje, jezikovne družine, romanski jeziki, slovanski jeziki. 


\section{ABSTRACT}

\section{Intercomprehension - When Everyone Speaks Their Own Language and Understands Others}

Intercomprehension is a communication practice where two persons speak their mother tongue and are able to understand each other without being taught the language of their adressee. It is a usual practice between languages that belong to the same linguistic family, for example Slavic, Romance or Germanic languages. In the article, the authors present the notion of intercomprehension as an alternative to communication in English as a lingua franca. That kind of communication was known among Scandinavians, whereas the first teaching method was developped for Romance languages (EuRomCom) at the beginning of the 21st century. Today, more methods exist including German and Slavic languages. In the article, the authors are enumerating some of them and also give a short outline of existing practices.

Keywords: Intercomprehension, language families. Romance languages, Slavic languages. 